\title{
Ekphrasis as Discourse Semiotic Blending of Differing Art Media Texts
} Kira Andreeva*

Tyumen State University, Ulitsa Volodarskogo, 6, Tyumen, Tyumen Oblast625003, Russia

DOI: $10.36347 /$ sjahss.2020.v08i09.004

| Received: 01.09.2020 | Accepted: 08.09.2020 | Published: 17.09.2020

*Corresponding author: Kira Andreeva

Abstract

Original Research Article

The paper introduced innovative approach to ekphrasis connected with the new interest of scholars to it at the time of continuing studies of different art media forms. The notion of ekphrasis was well known since the time of ancient rhetoric, but at present it needed corrections due to the new reality of multiplicity of artistic semiotic representations of the same phenomenon in different ways. The aim of this article was to explore and prove the validity of reconsidering the changed status of ekphrasis. In this study it was recognized as a complex dynamic semiotic phenomenon born in the result of fusion of two semantically identical, but formally different representations of the same artifact by different art media forms. The empirical part of the research was provided by the English translation of G. Leroux's novel: "The Phantom of the Opera" and corresponding, in content, paintings. The image of the main character was chosen as the goal of the study. Innovative interdisciplinary tools were chosen for comparative research. Results confirmed the principal validity of the research.

Keywords: Ekphrasis, creativity, cognitivediscourse paradigm, integrated analysis, image characterization, blending. Copyright @ 2020: This is an open-access article distributed under the terms of the Creative Commons Attribution license which permits unrestricted use, distribution, and reproduction in any medium for non-commercial use (NonCommercial, or CC-BY-NC) provided the original author and source are credited.

\section{INTRODUCTION}

The article explored ekphrasis, as the result of blending of asymmetric Art media texts. The notion of ekphrasis dated back to ancient times. The term was created in ancient rhetoric, in Greece, with the desire to make texts more expressive, emotionally coloured. Initially ekphrasis was understood as the literary description of some object represented in Art. At first ekphrasis was most usually applied to the correlations of poetical texts and paintings. In the course of time the examined notion underwent further considerable broadening and changes.

A brief survey of theoretical background of late contributions devoted to the study of ekphrasis supported the fact of stable presence of this theme in scientific research. Although detailed information providing complete listing of the works of scholars in this field was out of the scope of this research some relevant references should be mentioned. From historical point of view it became evident that most papers of the end of the twentieth century often followed the traditional approach to ekphrasis, yet often concentrating on the study of its special features, as well as on some original observations. Several examples should be adduced. Historical development of the notion was presented by the work of Nancy Moore
Goslee and James Hefferman [1]: "Museum of Words: the Poetics of Ekphrasis from Homer to Ashbery", in Studies in Romanticism. Claus Cluver [2] published the paper: "Quotation, Enargeia, and the Function of Ekphrasis" in the edition by Valerie Robillard and Els Jengeneel: Pictures into Words: Theoretical and Descriptive Approaches to Ekphrasis. Robillard Valeries' own article [3]: "In Pursuit of Ekphrasis an Intertextual Approach"appeared in the same edition, as was quoted above. Several articles were published by Yakobi, Tamar in the nineties of last century. Full references would be presented at the end of this article [4-6]. In one of Yakobi Tamar's articles an original metaphor identifying ekphrasis, as an umbrella covering various forms of rendering object in words was used [4]. This new image was creative and dynamic, original, at that time. Also, other special collections of articles devoted to the studies of ekphrasis were published in the nineties of XX century.

At the beginning of the new century more works based on the analysis of the interface of literary texts and musical artifacts appeared. In general, application of ekphrasis in XXI century was characterized by the majestic broadening of differing types of interfaces which could include even more than two correlated artifacts based on operas, musicals, films. Digital technologies provided more efficient and 
quick access to all of them via internet. Even terminology, due to innovative studies, included many new terms: transmedia, multi-media, art-media, interface culture, art at the crossroad. In answer to this, scientific research also substantially broadened its horizons. The specificity of the moment was that the new appearing publications varied greatly: from those limited by empirical research (close, qualitative) to global theoretical ones discussing fundamental problems, such as synthesis of arts, art as ingredient of culture, media art tangible interactions, transmedia frictions: the Digital, the Arts, the Humanities, and others, the like. Some examples from the first group, oriented more on empirical research, could be adduced. A very professional article based on contemporary methodology was published by Peter Verdonk [7], under the title:"Painting, Poetry, Parralellism: Ekphrasis, Stylistics and Cognitive Poetics", in the Journal Language and Literature.Other references could be: the article by Manana Rusieshvili [8]: Ekphrasis and its Multifaceted Nature: Ways of the Usage in Literature and Cinematography. In International Journal of Literary Humanities. Volume 13, Issue 3. Also the article "New Approaches to very Traditional Notion 'Ekphrasis' in the Dialogue of Linguistics and Art ', by Kate Belovorodko and Kira Andreeva, published in the Journal Universum: Philology and Art, № 11 (33) was connected with the first direction [9].

Among the articles written by authors, representing the second trend (based, rather, on theoretical approaches) I would like to mention Thomas Enrique [10], with his article: How the Arts Can Help Tangible Interaction Design: a Critical Reorientation" in Informatics, 4, 31; also the paper by Lev Manovich [11]: The Language of New Media. In Leonardo Book Series. The MIT Press: Cambridge, MA, 2002. Thomas Enrique's main objective of his work was to confirm the status of art specialists in the studies including the process of merging of humanitarian disciplines. He, actually, questioned: "Why is the artistic collective not so much present at tangible interaction labs? Which role should artists assume at human-computer interaction? ". And in conclusion, he asserted: "The Arts create a type of knowledge which is not afforded by traditional HCI (Human Computer Interaction) methodologies especially in the case of embodied technologies": Thomas 2017. This call for real fusion appeared to be absolutely reasonable! Yet, some scholars were more optimistic on this question. Thus Mats Jansson [12], in the paper "Ekphrasis and Digital Media". In Poetics Today. 39(2). stated: "Digital 'remediation' has given the ekphrastic writer a new creative freedom to work with visual arts.": Mats Jansson 2018 [12]. So, many problems connected with the study of ekphrasis, as well, as with the synthesis of arts remained open up till the present moment.

Thus the, most evident RESEARCH GAP, concerning the status of ekphrasis in the interface of artifacts, was the problem of adequate choice of research methods. Significant progress in the study of ekphrasis, at the crossroads of so many differing and asymmetrical systems (which we consider to be semiotic ones), inevitably led to the expected search of most reliable way of analysis. This formed the real RESEARCH GAP calling for investigators' new studies. The factual absence of adequate tools of analysis was registered for the study of texts based on differing forms of perception. This article dared to offer one variant of experimental testing of the use of multidisciplinary approach.

The AIM of this article was TO TEST THE VALIDITY OF CONSIDERING EKPHRASIS, as THE RESULT OF BLENDING of COMPARATIVE SEMIOTIC FORMS OF EXPRESSION OF (AT LEAST TWO) TEXTS OF ART MEDIA ASSYMMETRIC CHARACTER. Innovative complex methodology was applied in the analysis, based on the results of cross-cultural study of interdisciplinary research of correlated disciplines: psychology, psycholinguistics, stylistics, cognitive poetics, even, brain studies.

Empirical analysis was limited to comparative analysis of the construal of ekphrasis as the main image character's qualities' blending, based on Gaston Leroux's novel "The Phantom of the Opera" [14]. The interface of literary text and corresponding, in content, pictorial images was the principal objective for analysis. The English version of the novel was adduced for analysis. Thus, linguistic and visual images were juxtaposed. The comparison evidently provided semiotic and asymmetric difference which, actually, confirmed the need of the use of adequate methods applied in research.

\section{RESULTS OF EMPIRICAL RESEARCH STARTING INFORMATION}

Brief general outline of the article's empirical material should precede the content. The novel "The Phantom of the Opera", created by the French writer Gaston Leroux, was first published in 1909-1910, by Pierre Laie. The English printed version (145 pages) appeared in 1910. The content was closely connected with real historical events happening at the Paris Opera House which happened before the publication. Mysterious happenings included the finding of the young ballet dancer's skeleton inside, and the mysterious and tragic crash of the biggest chandelier at the Opera; as well, as other mysterious facts. Hence, Leroux's book was identified as a Gothic novel portraying mystery, horror and romance. The latter was connected with the novel's narrative line concerning the love triangle between the young beautiful soprano singer Christine Daae, her lover Raoul and the Ghost of the Opera: Eric, "the Angel of Music", madly obsessed by his love to Christine. 
The book did not get proper recognition at the time of its publication, the initial reviews of critics were not very favourable. It should be assumed that, unfortunately, the critics somehow missed Leroux's gift of creativity, vivid imagination, literary art, his innovative discoveries of new scientific achievements The evident error was proved and corrected by the real storm of all sort of future recognition, in the forms of various adaptations: stage performances, opera versions, musicals, films. The most well-known and popular, up till now, turned out to be: the Andrew Lloyd Webber's musical.

The French original had also several translations into English and many other languages. The first English translation was performed by Alexander Teixeira de Mattos. The privilege for scholars was that this edition was not recognized as copyright (being published more than a century ago). The search of pictorial images (internet photo variants) was considerably more complicated. The first painter who illustrated first editions was Andre Castaigne, and his featured colour plates (five photo copies of them) were available. Pictorial material for this research was provided by photos from internet. Different illustrations were also mentioned in official sources: by Robert Schoolcraft, Max Douglas, Waine Anderson and others. They were done for different versions of narrative, different editions and differing translations. The access to most sources was, as could be understood, limited. Internet copies provided examples for asymmetric comparison with literary texts.

The results of research confirmed the preliminarily stated hypothesis. Ekphrasis of the Ghost's (Eric's) Image was constructed by consequent steps, by and by, up to the final stage of blending of the main Eric's qualities. Ekphrasis was realized as the result of cognitive, dynamic process of its creation. The analysis was performed with the help of Discourse Cognitive Paradigm of the semiotic interface of two asymmetric texts belonging to two different Art media forms: original literary and visual pictorial images. The analysis of the latter was especially complicated, as special methodology is still under discussion (whereas linguistic analysis, on the contrary, is well developed). The innovative notions and tools of closely correlated disciplines, mentioned above; among them, such as: perceptional keys, visualization, perception, auditory signals," the mind of the eye"; integrity of imagemaking and; and most of all, creativity and the gift of the author's imagination contributed greatly to the empirical research. Many more explorations were vital in supporting of the results.

\section{Discourse Actualization of Phantom's Image by Different View Points}

Gaston Leroux began his novel: THE PHANTOM OF THE OPERA" with a very clever and efficient device; from the start, he provided his readers' interest and immediate immersion into the text by giving a very detailed content of twenty six items. Unfortunately, the article's limitations do not give the opportunity to quote it. Yet, some commentaries on the text could not be missed. The art of Leroux's creativity was demonstrated from the start. The author managed to attract the vivid interest and excitement of readers by his mastery at once, by the lexical choice of the used vocabulary in the Content: the words 'mystery', 'ghost', 'enchantment', 'love story, 'the cellars of the opera', 'trap-doors', 'torcher chamber', 'scorpion could not fail the readers' instant desire to know more, by quick immersion into the story. More experienced recipients could be attracted, as well, by mentioning in the Content the names of the well- known literary and opera characters, such as Faust and Margarita, also the allusion to the Greek God: Apollo, which raised their evaluation concerning the high general cultural level of the author.

The novel's text was elegantly built, with the help of the main narrative, embedded in between PROLOGUE and EPILOGUE, the so-called frame construction. The author went on to keep the readers' attention by the basic themes of the novel connected with enigma, love, music , kindness, death, associated with tragedy, gothic horror.

DISCOURSE-COGNITIVE PARADIGM of Leroux's novel, which was considered as the leading one for the text organization, depended much on gradual construal of the images of the main characters: the Ghost (identified later, as a real man: Erik) and Daae, the beautiful soprano, the girl he was obsessed with. The realization of the aim of the article: to present EKPHRASIS of the PHANTOM of the Opera (Erik), as mentioned above, heavily depended on the use of adequate methodology. Classical psychology's opinion supporting the principle of INTEGRITY OF IMAGE by the prospected recipients was accepted in this analysis. Yet, EKPHRASIS, representing this integrity in literary text, was not given by the author from the start, but was created gradually, step by step, corresponding to the narrative progression. It was proved in this part of the present analysis. Discourse actualization of Ghost's Image was exemplified gradually, by small extracts of Opera's accountants' impressions of their real and imaginary meetings with the Ghost. Most of them presented his verbalized portraits. Below some examples would be adduced.

Joseph Buquet, the chief scene-shifter, had run against the ghost on the staircase and saw him only by a second: 'He is extraordinarily thin and his dress-coat hangs on a skeleton frame. His eyes are so deep that you can hardly see the fixed pupils. You just see two big black holes, as in a dead man's skull. His skin, which is stretched across his bones like a drumhead, is not white, but a nasty yellow. His nose is so little worth talking about that you can't see it side-face; and THE" 
ABSENCE of that nose is a horrible thing TO LOOK AT. All the hair he has is three or four long dark locks on his forehead and behind his ears.'

Parallelly, a photo illustrating the ghost, from the cover of one of the editions of Leroux's novel, was adduced (which, unfortunately, had not any reference concerning its painter), closely corresponding to this linguistically presented above description.

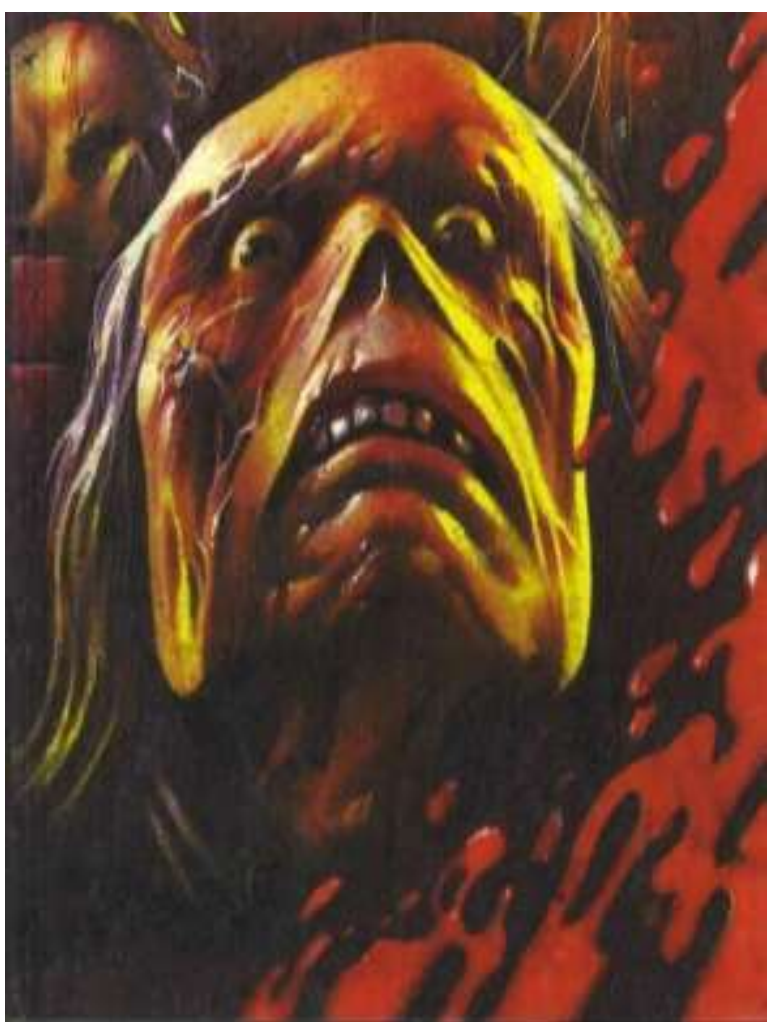

Fig-1: Photo of the pictorial image of Opera Ghost, from the cover of the Russian edition of the book 'Gaston Leru. The Opera Ghost'(1993).Translated by Barsukov, Yuryi. Moscow: Krim Press. No reference to the painter was given

Other encounters and corresponding pictorial images could also represent different view points of Opera guests, who all of a sudden, witnessed the Phantom: 'the attention of one of some of the guests was diverted by the discovery, at the end of the table of that strange, wan and fantastic face, with the hollow eyes, which had already appeared in the foyer of the ballet and been greeted by little Jamme's exclamation: 'The Opera ghost!'.

Surprise and wonder resulting from these unexpected encounters merged very quickly in voices of people, with the expressions of general excitement and real horror. All unhappy happenings: falls, loss of some objects were associated with the Ghost: he was the one to blame. One more illustrating photo could be adduced below.

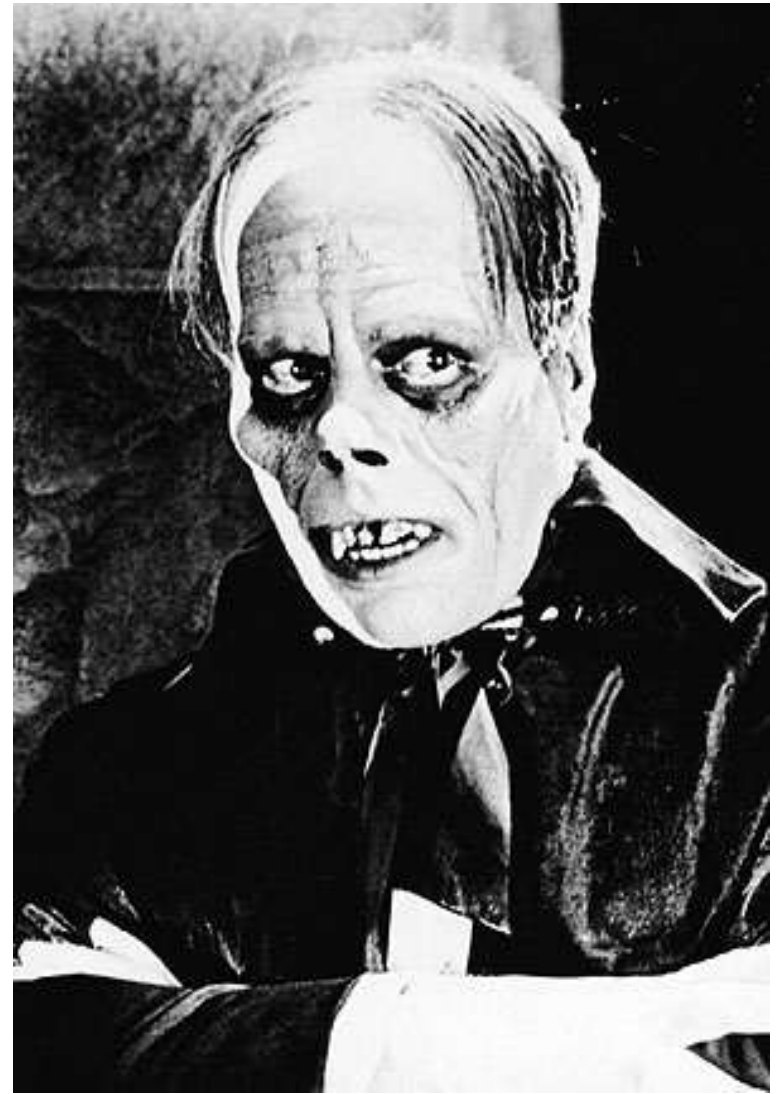

Fig-2: Photo from internet pictures of images of the Ghost of Opera

The content of actualization of the Ghost's image in the Leroux's text and in the adduced Photos was practically identical. But the forms of expression differed which corresponded to their recognition as asymmetric semiotic differing artifacts. Semantically, both of them presented the Ghost's outer portrait, although in the first case it was expressed dynamically, by linguistic forms; whereas in the second (pictorial representation) it was statical, visualized image. Thus, comparative analysis presented problems. First, empirical research was devoted to the linguistic analysis of the English literary text. All descriptive texts: fragmentary sketches of the Ghost's image represented mainly his appearance. They could be analyzed via the basic categories of cognitive poetics as the representing the category of Point of View and the Category of Voice. We also treat them as constituents of DISCOURSE PARADIGM, because in the text they were given as short fragmentary encounters of Opera attendants and officials with the ghost and voicing their impressions, mainly in the form of Direct Speech. The descriptions mainly included the characteristics of details of the ghost's face, clothes, quick movements, away from people. Linguistically, it was represented mainly by corresponding lexical units: nouns accompanied by epithets: skeleton (frame), so deep (eyes), with big, black (holes), little (nose), (a face) so pallid, so ugly; strange, wan and fantastic; (nose) long, thin and transparent; a false (nose), supernatural (being). Some comparisons were colouring the negative 
impression: his skin, like a drumhead; the ghost... like a shadow; this specter... dressed like a man of fashion. Thus, the mysterious man got the nickname the Ghost of Opera. All people terrified by his sight expressed 'unspeakable terror'; 'the absence of that nose was a horrible thing'. The way of the ghost's walking was charactarized as very slow: 'like a real ghost, he made no noise in walking'. People evidently did not like him. All unfortunate happenings were attributed to him. Thus, the Ghost's image was verbalized explicitly, as well, as the general atmosphere of horror. The colour nomination: BLACK accompanied constantly his image.

Pictorial images: in Figures 1 \& 2 evidently managed to provide instant immersion of readers, due to quick perception and eye -visualization. Semantically, the same (literary) image vision was transferred, but in this case the linguistic tools which were applied in the literary text were not available. The viewer experienced the negative emotion at once noting the same details of the ghost's face, with the help of visual codes: deep hollows in the eyes' places, two pits in the place of the nose in Fig-2. The expression of the face was sinister in all photos, the basic colours were

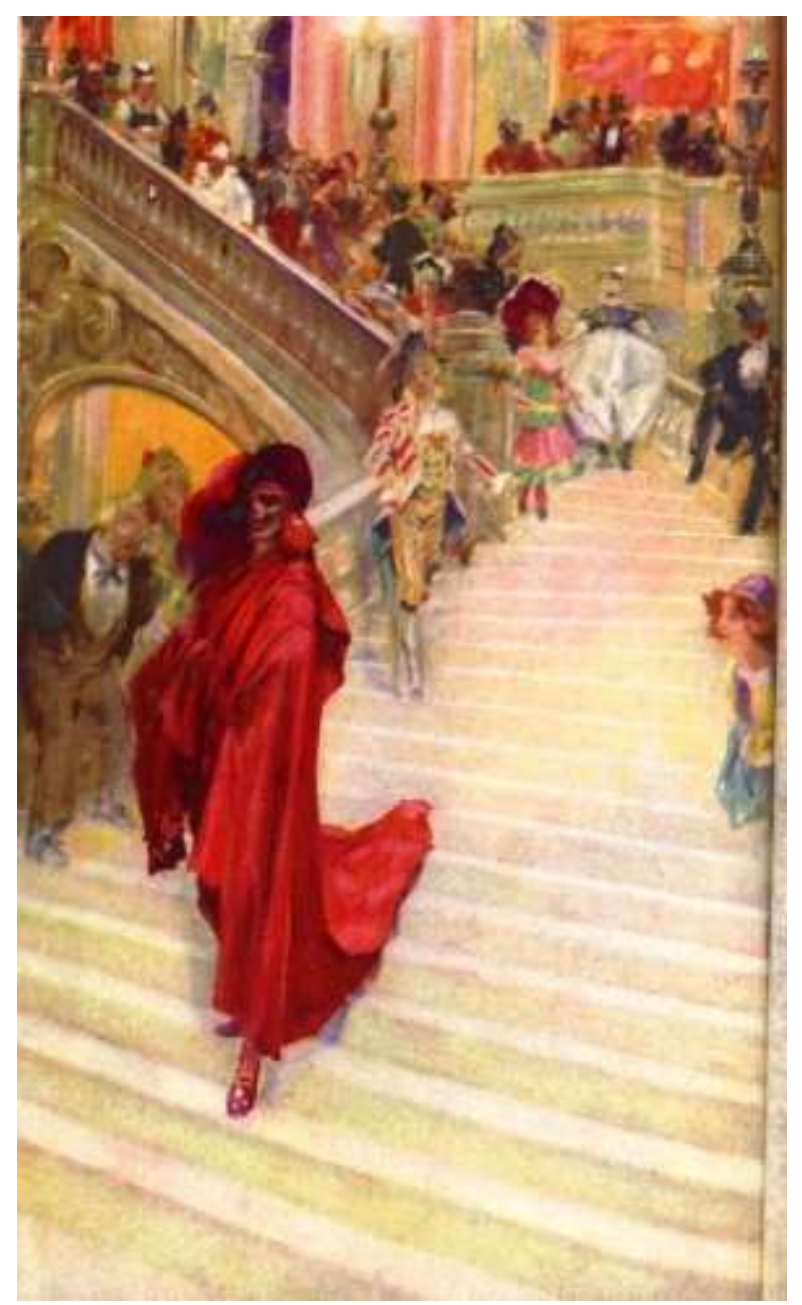

Fig-3: The Photo of the famous picture by Andre Castagne the Phantom of the Opera grey and black. In Figure-2 hands were portrayed which also looked threatening. In Fig-2 the open left hand denoted prohibition to approach. In all cases static positions were actualized.

However, quite a different impression was produced upon the viewers of the Opera, and later by the readers of the novel, during the masque ball. It was masterfully visualized in the famous picture by Andre Castagnes: "The Phantom of the Opera". In this picture the Ghost, in his masquerade dress, was slowly stepping down the magnificent stair-case of the Opera House. The literary actualization which was also very impressive would precede the visualized version. 'As Raoul once more passed through the great crush room, this time in the wake of his guide, he could not help noticing a group crowding round a person whose disguise, eccentric air and gruesome appearance were causing a sensation. It was a man dressed all in scarlet, with a huge hat and feathers on the top of a wonderful death,s head. From his shoulders hung an immense red velvet cloak, which trailed along the floor like a king's train, and on this cloak was embroidered in gold letters, which everyone read and repeated aloud, 'don't touch me! I am the Red Death stalking about' Figure-3.

The literary actualization which was no less impressive, given in the photo above, displayed the use of most impressive epithets: eccentric and gruesome (Ghost's appearance), causing a sensation; wonderful (death's head); an immense red velvet (cloak); violently seized, the furious (grasp of Death). Also comparisons, very expertly supported this magnificent picture: the cloak trailed along the floor, like a king's train; the man crossing his way ran away, like a very mad man. Thus, the interface of both examples: the literary description and the pictorial image had asymmetric actualizations but both appeared to be very impressive, deserving every praise.

\section{Representation of Conceptual Sphere of The Ghost's Image}

The analysis of the enigma of construal of the inner Phantom's image was much more complicated. It was kept closed in the novel even for Christine Daae, whom the unknown voice taught music, being invisible, and much later, presenting himself as a man in black mask . For her he always remained the hidden Angel of Music. Leroux disclosed characteristics of the Ghost's inner image, step by step, in the most important part of the novel, mainly, with the help of big textual sections of Christine's, Raoul's, the Persian's and other people's discoveries and revelations about their selective communicating with him. Mostly, it was represented by big passages of monologues (presented in Direct speech). For evident reasons, this empirical material was only partly presented in this part of the article, as the main accent was on the summarizing the results of research and specially outlined in the form of schemes. 
Leroux's penetration into the Ghost's inner image started very logically from the description of his Voice, via the auditory key of perception (which in future became a real discovery for the opera and musical presentations). That was the one, among many, secrets or special riddles, used by Leroux, for evident reasons of stimulating vital interest of his prospective readers. The first discovery of the existence of the mysterious voice, coming, as if from the wall, was granted to Raoul, Christine's friend in her dressing room. Christine Daae, one of the main characters of Leroux's novel, was better acquainted with it, but also never saw its owner. She was the young beautiful soprano who managed to get the fantastic reception of the public for her wonderful singing at the Opera. The Voice appeared in her life, as her anonymous teacher of music, "the voice without body", coming from the wall of her dressing room. She was enchanted by the beauty of music and of the voice. And music classes were very useful, professional and led her to big success. Below some of the textual illustrations would be given.

The first text presented Raoul's perception of the Voice. At the same time he saw the rapture of Christine enchanted by those sounds. "Christine's face lit up. A smile of happiness appeared upon her bloodless lips...The voice without a body went on singing, and certainly Raoul had never in his life heard anything more absolutely and heroically sweet, more gloriously insidious, more delicate, more powerful, in short, more irresistibly triumphant. He listened to it in a fever...The voice was singing the Wedding-night song from Romeo and Juliet. Raoul saw Christine stretch out her arms to the voice." The extract was highly emotional, producing instant empathy. Very high degree of fascination was rendered by the masterful choice of words with positive connotations: the nouns smile, happiness, rapture, fever, Wedding-night; adjectives used as attributes: sweet, insidious, delicate, powerful, triumphant; reference to the young lovers: Romeo and Juliet, they all contributed greatly to the expression of the atmosphere of enjoyment. Also reiteration, with epithets: adjectives in comparative degree intensified the effect.

One more passage for supporting the impression: Christine "seemed to be listening... Raoul also listened... Whence came that strange sound, that distant rhythm?....A faint singing seemed to issue from the walls...yes, it was as though the walls themselves were singing!...The song became plainer... the words became now distinguishable... he heard a voice, a very beautiful, very soft, very captivating voice...but, for all its softness, it remained a male voice...". The enigma of the described phenomenon could not but attract the readers' vivid interest and the desire to find the explanation!
Music possesses an immense power, and Christine involuntary fell under its spell. She was determined to solve the enigma, and the mysterious Voice (of her Angel of Music) occupied her thoughts more and more. After her perfect success at the Opera the voice told her that she was to love him, and once she noticed that she somehow was no longer mistress of herself, but became HIS thing. Christine suddenly disappeared; she was kidnapped by the man wearing a black mask and awfully frightened. The man turned out to be the person with 'the Voice', he told her that his name was Erik. He brought her to his abode situated deep underground, under the building of the Opera. Erik confessed that he was deeply in love with Christine, spoke much about music, sang to her with his beautiful voice. Christine relaxed a bit; she learnt much about his talents: he composed music, was very creative, played various musical instruments. They began to sing the duet of Desdemona and Othello, a very emotional aria experiencing the presence of love, jealousy and hatred. Under the influence of music Christine made a fatal mistake: she tore of the mask from Erik's face. Telling later this story to Raoul Christine could only pronounce: "Horror! Horror! Horror!" That was what she saw: "the four black holes of its eyes, its nose, and its mouth; the mighty fury of a demon; AND NOT A RAY OF LIGHT FROM THE SOCKETS, for, as Christine learnt his blazing eyes could be seen only in the dark. Erik uttered a cry of grief and rage, and Christine was horrified. This highest point in narrative progression was characterized by the use of triple reiteration of the word "Help!", it strengthened the impression of horror. What was even worse, she saw the face of a dead man. The present description was plain and direct presenting horrible details. It should be stated that mostly pictorial images of the Ghost's appearance were commonly met. In contrast, portrayal of narrative steps, of inner emotions, as well, as speech characterization could be expressed in this situation only linguistically. Pictures possess equal, but only visual abilities for transferring eye perception and visualization. Auditory perception (of voice) was not possible. Thus, it was not easy to find examples for adequate comparison. Yet, I managed to find two suitable cases for this purpose. In Fig.4, exemplified by photo, Erik, with half-torn mask from his face, was holding it with his trembling (the impression received from the slide).fingers. His face was wrinkled, dark; eyes half-closed, with tears and an expression of deadly torture. 


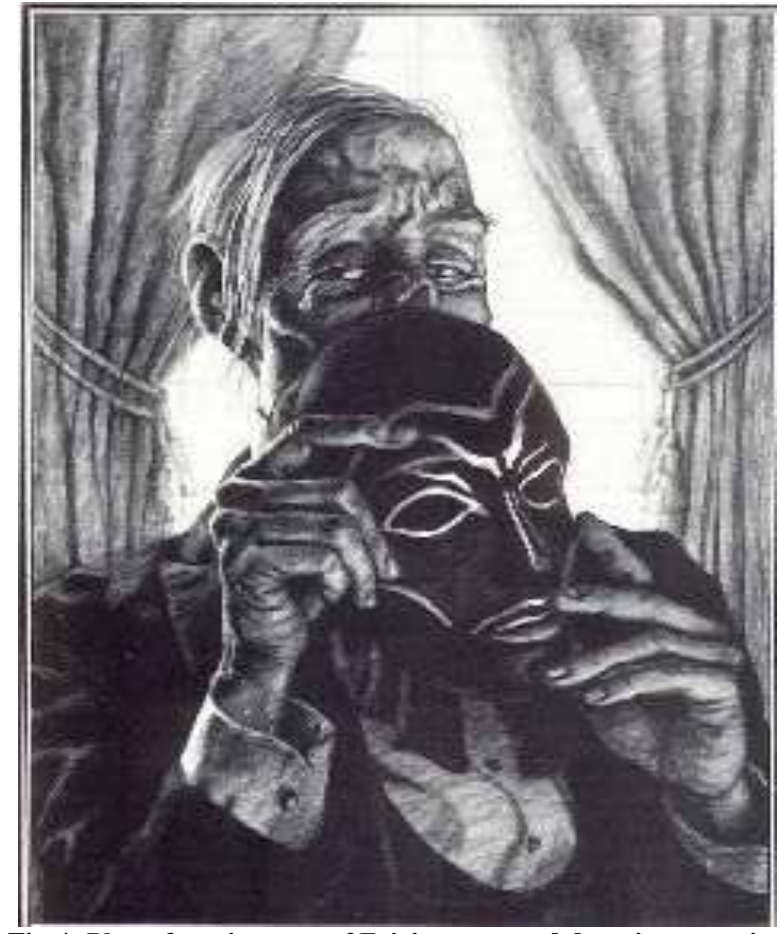

Fig-4: Photo from internet of Eric's agony and despair at opening his real face

In the next photo: Fig-5 participants of this tragedy: Christine and Erik were portrayed standing a little apart from each other. The man's face was wholly covered. Christine, having realized her fatal mistake, was standing, also covering her face with her hand. Her eyes were widely open, she was staring with pity at Erik.

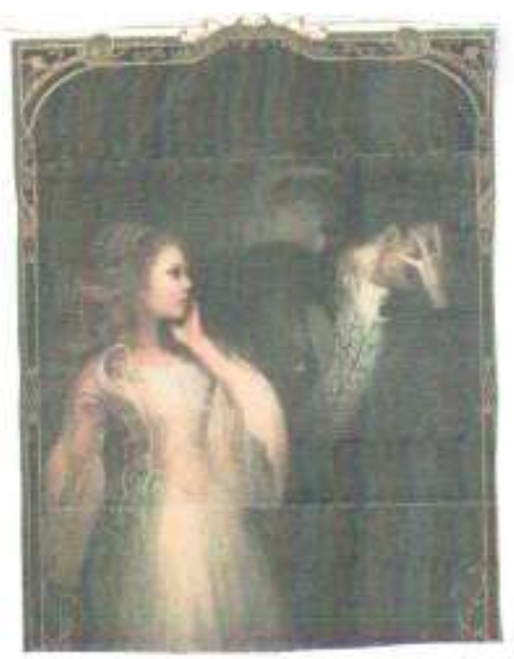

Fig-5: Horror at revealing Eric's secret
Before this incident Erik warned Christine that she should never try to look at his face, but she did not follow his words. His terrible secret was discovered. It was a real shock for both of them. But, for Erik, it was much worse. His most precious dream came to its end, it meant the crash of his life. First, he became furious. He could not control his emotions. He became violent, rude to the girl whom he worshiped, and was madly in love with. Later description presented Erik's highest stage of madness, rage and, later, despair and suffering in this horrible and unexpected situation. His uncontrolled cruel actions were actualized linguistically by narrative steps of frenzy and cruelty. The information concerning Erik's actions was transferred by instances of his direct speech. Not only the use of visual codes was activated by the author, auditory codes were activated as well, with the help of special verbs: (he) cried, roared, hissed, shouted. This episode was the most important in the novel's progression creating its climax.

Gradually, the storm was over. Erik went to another room and began to sing the most bewitching music Christine had ever could have heard: his newly composed: aria of Don Juan, the Triumphant. Christine also managed to control her temper, came to Eric and managed to calm him down. She was kind-hearted, wise. They cried together, their tears mingled. She let him kiss her. He let her go away. The end of their relations had positive outcome for the girl. She promised to be the living bride of Erik, and return his ring to him after his death (as he stated he would die soon, for love). So, for Christine it was a happy end. The latter examples vividly illustrated evident dynamics in Eric's nature, his changes from violence to peaceful state, he became reasonable, kind-hearted and even noble-minded, understanding the girl whom he loved and giving her freedom.

Thus, the provided empirical material gave opportunity to sum it up it and outline the Conceptual Sphere of Eric's characterization. The Conceptual Sphere was understood here, as a complicated hierarchical sum of Eric's basic, mainly, inner, concepts. I found it reasonable to accept recognizing of the validity of paradigm including three basic (core) layers of individual's characterization. The basic layers included: 1). BIOLOGICAL STATUS OF INDIVIDUAL (outer identity and properties: the living person having face, body identification, typical gestures, face expression, typical face expression; 2). SOCIAL LAYER: the place in community, work and professional sphere, social activity, family, outward contacts and interests; 3). INTELLECTUAL (INNER) WORLD: mind and perceptional activity, embedding moral, aesthetic and cultural principles. All three layers of CONCEPTUAL SPHERE contained considerable number of special concepts, often presented in oppositions: like good - bad. Concepts were actualized, 
in our case, by linguistic and specific pictorial signs of asymmetric Art systems.

\section{Below Corresponding Examples Would Be Given}

The definition of the main character's outer status presented certain difficulty: If IT WASA GHOST OR A MAN?" Practically all opera attendants, actors, actresses, spectators were sure that it was a ghost, or in other terms, 'the Phantom of the Opera'. He had horrible deformed face, two holes for eyes, almost no nose (it was very thin, transparent). In short, his appearance was characterized as ugly, supernatural, wan, strange, horrible. Linguistic actualization closely corresponded to its pictorial image, in the form of his portrait. Only later Christine identified him as a real man, her tutor, with a beautiful voice.

The SOCIAL LAYER was admitted later in the following way: "I am not an Angel. Not a genius, nor a ghost...I am Erik!". Thus, in the end the image was identified as a real man, deformed since childhood. Most time at the Opera he was hiding from people, although he was well-off and even had his private Box 5 at the Opera. He taught music to Christine Daae. His rare communication with people was very complicated. 3). Eric's INTELLECTUAL INNER WORLD (his inworld) was decoded in the novel, part by part. It was explicated during Eric's encounters with Christine, and decoded during her later impressions, in the form of direct speech, linguistically. It could be cognitively represented with the help of corresponding concepts of different types. The main (CORE) concepts contain many minor concepts reflecting highly complicated structure of Eric's image. Some cases of Core and Minor concepts could be adduced. INTELLECTUAL QUALITIES presented an opposition of Positive and not so positive features. To Eric's positive ones were: penetrating mind, high intellect, creative activity, sharp intelligence, constructive ideas, gift of new discoveries, mind of a genius. To the opposing qualities referred: refusal to survive, inability to resist, ruin of his love. AESTHETICAL AND ETHIC CORE QUALITIES also presented an opposition. POSITIVE CONCEPTS included: Art knowledge and understanding, musical talent, beautiful voice and singing, skillful violin performance, expert teaching, creative mind, inspiration. NOT SO POSITTIVE and SOME NEGATIVE were: destructive nature, ruining, revenge, defeat. All THREE LAYERS of IMAGE CHARACTERIZATION were always connected with one more additional SPHERE DENOTING
PERSONAL FEELINGS AND EMOTIONS, also falling into POSITIVE AND NEGATIVE ONES. To POSITIVE belong: first love, devotion, tenderness, romance, sacrifice, kindness, noble soul. NEGATIVE ONES were disappointment, jealousy. pessimism, anger, cruelty, hatred, destroyal, murder. .In short, the Ghost's image characterization was presented with the help of SCHEME 1. It included the three CORE Layers (mentioned above): the first was denoting OUTER IMAGE (appearance: face, body); the second expressed SOCIAL IDENTITY; and the third actualized the INNER WORLD (mind qualities). All three layers were accompanied by concepts of EMOTIONAL LAYER which appeared to be normal and usual in the life of any human being at all stages of life. The separate concepts, included into all spheres, were identified by cognitive research and well investigated by now in linguistics.

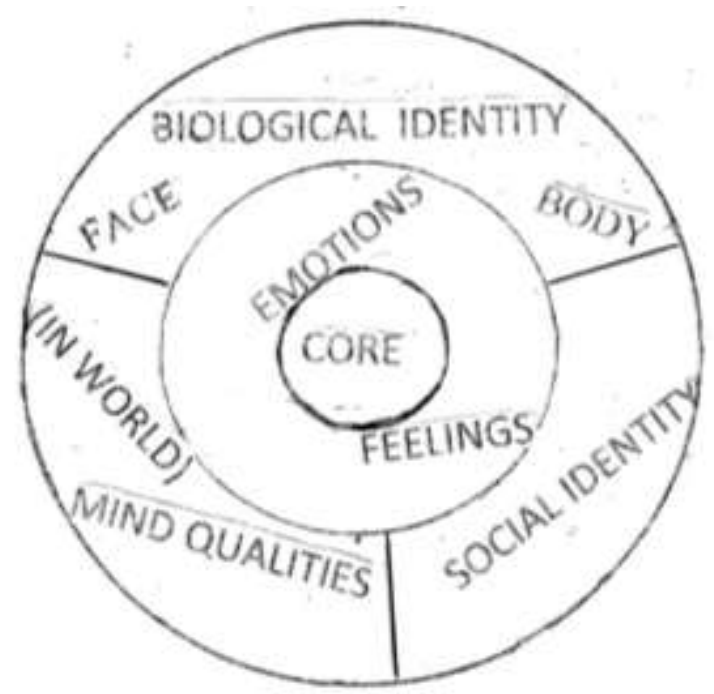

Scheme-1: Conceptual Sphere Of Physical And Mental Image Characterization, Including Three Basic Conceptual Layers, With The Emotional One

Ekphrasis as Cognitive Blending of all Aspects of The Ghost's Image Based on The Interface of Literaryand Pictorial Devices

Contemporary Cognitive research, based on the studies of Fauconnier and Turner's ideas, got an efficient way of revealing text semantics, with the help of the economical scheme disclosing gradual stages of development of the text, which could relevantly present gradual steps of creating ekphrasis in narrative progression . The method became known as BLENDING. 


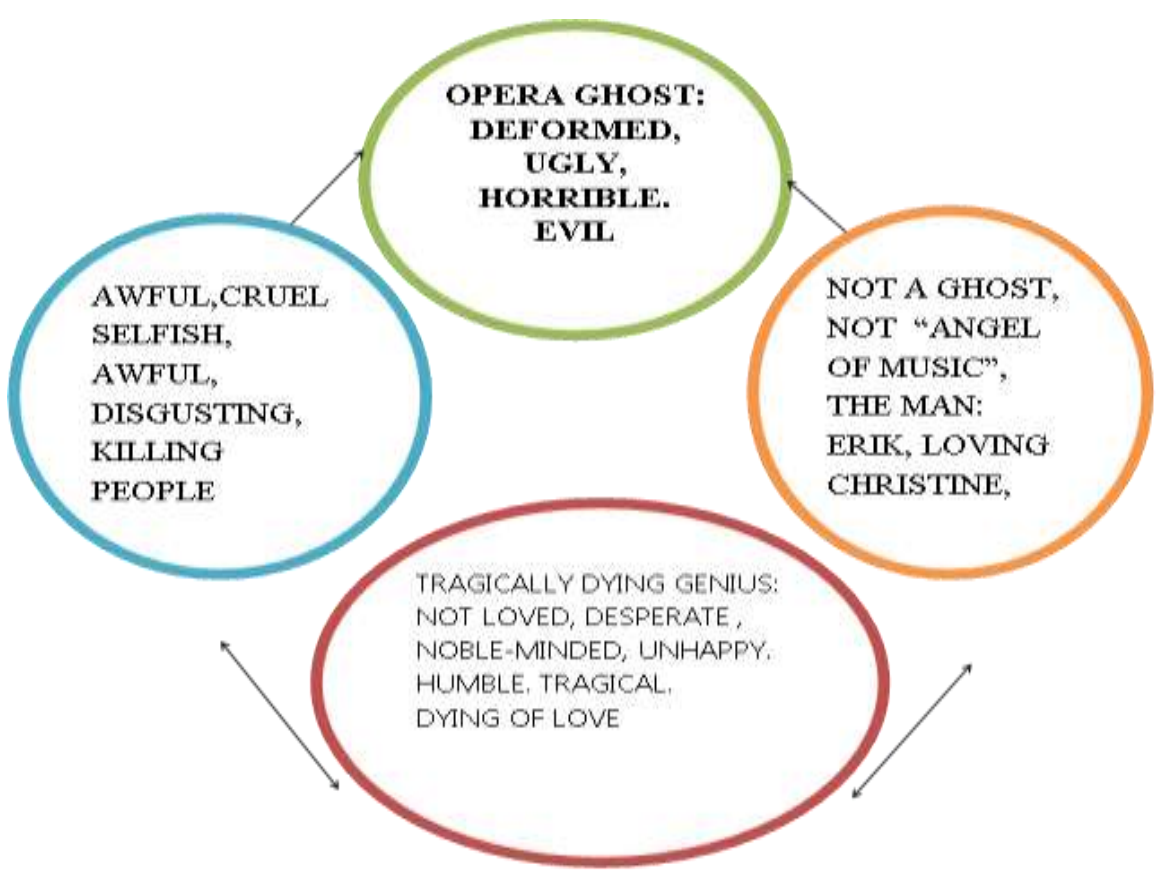

Scheme-2: Blending of Ekphrasis of the Ghost's Image Characterization

The four circles in this SCHEME denoted Four Cognitive Layers, or Mental Spaces. The first, at the top, denoted the Initial Space (OUTER LAYER, in our case). The circles 6 on the left and right, were usually identified as INPUT SPACE 1 AND INPUT SPACE 2, understood as gradual changes in the narrative development connected with the gradual steps of mind perception, at CONCEPTUAL LAYER. The circle at the bottom was called Blending Space. It marked the result of fusion of all Ghost's positive and negative features into the generalizing EKPHRASIS. The finally received information was later extended due to the commentaries of the Persian (the man who knew Erik well), by the facts of Erik's creative mind and technical discoveries. The validity of usage of this Scheme of Blending was proved. A similar example of its application could br found in in another article [13].

\section{DISCUSSION}

The undertaken, mostly empirical, research proved the chosen aim, although, it was limited in scope. Actually, this literary text could be compared with different other art realizations. Yet, as is well known, without ANY practical analysis, science is dead. The outline of possible discussions was already mentioned in the Introduction of this article when the brief theoretical survey was given. The main existing problems were outlined and even partially discussed, via the opinions of scholars in the cited articles. The latter were divided into those devoted to mainly empirical (disclosing close, qualitative) research. Another approach opened the platform of exploration of theoretical issues. The most important and actual problem is connected with the lack of objective methodology of systematic research of art media texts based on visual, (or auditory) perception. What is more, not all scholars even admit the real possibility of such scientific explorations. One reasonable example of such opinion belongs to one of the best researchers of the twentieth century, the highly respected specialist in the field of physics: Niels Bohr, who wrote: 'The reason why art can enrich us lies in its ability to remind about harmonies inaccessible in systematic analysis': Bohr [15]. The art scholars today are still in the process of search of perfect answer to this opinion. What is clear is the undeniable fact of difficulties of research of texts of asymmetric art media. Art specialists insist that their opinions , as expert ones should also be recognized. To add, multidisciplinary scientific results could contribute greatly to the success.

One more problem is of vital importance is: if explorations of the interfaces of different art media forms lead to the explanation of ekphrasis, or to the bigger phenomenon: of the study of synthesis of asymmetric art forms. Science is to continue research in this field.

\section{CONCLUSION}

The article confirmed the newly changed status of traditional ekphrasis connected with New time, new reality of multiplicity of research opportunities, of empirical options in the sphere of interfaces of various art forms, in new integrated technologies. The research proved the validity of considering the enrichment of the notion of ekphrasis which could render the extended knowledge of aesthetic, emotional information, in the interface of literary and pictorial texts. The studied ekphrasis appeared to present a complex dynamic semiotic phenomenon, born in the result of blending of literary and pictorial, semantically identical, but asymmetrical in forms of expression unity; yet, supporting each other in producing ever increasing artistic effect. 
Finally, I address my most deep and sincere gratitude to all respected academics who managed to lighten my enthusiasm and creativity in this noble study of the interface of literary and art media texts. I feel happy to thank professors Trevor Eaton, the first founding editor of the Journal: "Literary Semantics"; Michael Burke; Lesley Jeffries; Daniel Mac Intyre; Paul Simpson; Peter Stockwell; Michael Toolan for their kind and invaluable cooperation and assistance. And I also thank my former magistrate student Ella Bigwawa, for her help in finding pictorial images for this article. THANK YOU ALL VERY MUCH!!!

\section{REFERENCES}

1. Goslee NM, James H. Museum of Words: the Poetics of the Ekphrasis from Homer to Ashbery. In Studies in Romanticism. 1995.

2. Cluver C. Quotation, Enargeia and the function of Ekphrasis. In Valerie Robillard and Els Jengeneel: Pictures into Words: Theoretical and Descriptive approaches to Ekphrasis. 1998.

3. Robillard V. In Pursuit of Ekphrasis . An Intertextual Approach. In Valerie Robillard and Els Jengeneel: Pictures into Words: Theoretical and Descriptive approaches to ekphrasis. 1998.

4. Zonana VG. Artes plásticas y literatura de Mendoza. Piedra y Canto. 1999 Apr 24(5).

5. Yakobi T. The Ekphrastic Model: Forms and functions. In Pictures into Words: Theoretical and Descriptive Approaches to Ekphrasis. Ed. Valerie Robillard. 1998.
6. Yakobi T. The Ekphrastic Figures in Speech: Text and Visuality. In Word and Image Interactions, editions. Amsterdam, Atlanta, GA: Rodopy. B.V. 1999.

7. Verdonk P. Painting, Poetry. Parralelism, Ekphrasis, Stylistics and Cognitive Poetics. In Language and Literature: 2005.

8. Rusieshvili M, Yacobi T. The Ekphrastic Model: Forms and Functions. In Valerie Robillard and Els Jengeneel. 1998.

9. Byeloborodko K, Andreeva K. New Approaches to a Very Traditional Notion 'Ekphrasis' in the Dialogue of Linguistics and Art. In Universum: Philology and Art, №. 2016; 11(33).

10. Thomas E. How the Arts Can Help Tangible Interaction Design: A Critical Reorientation. In Informatics, 2017; 4, 31.

11. Manovich L. The Language of New Media. In Leonardo Book Series. The MIT Press: Cambridge, MA. 2002.

12. Janson M. Ekphrasis and Digital Media. In Poetics Today. 2018; 39(2).

13. Andreeva K. Cognitive Mechanisms for Literary Text Processing. In Cognitive Modeling in Linguistics. Ed. By Polyakov Vladimir and Solovyev, Valery. Cambridge Scholars Publishing, 2012.

14. Leroux G. The Phantom of the Opera. Pierre Laie. And its English Version. PDF copy: internet edition. 1909-1910.

15. Bohr N. Atomic Physics and Human Knowledge. Publisher: John Wiley \& Sons, New York. 1958. 